\title{
La fortuna de los grabados de Sadeler en el ámbito leonés. Algunos ejemplos de su seguimiento en escultura y pintura entre los siglos XVI y XVII
}

\author{
Manuel Arias Martínez \\ Museo Nacional de Escultura
}

\begin{abstract}
RESUMEN. Desde fines del siglo XVI el grabador flamenco Johan Sadeler creó, inspirándose en la obra de diversos pintores de su entorno, un amplio número de estampas que se difundieron rápidamente por toda Europa siendo utilizadas como fuente de inspiración por multitud de artistas. En territorio leonés, sobre todo en el ámbito del obispado de Astorga, diversos pintores y escultores utilizaron en sus composiciones estampas de dicho grabador, con especial fortuna para aquellas que Sadeler grabó basándose en obras del pintor Maarten de Vos. La importancia de estas estampas como fuente de inspiración para diversas obras de pintura y escultura desarrolladas durante los siglos XVI y XVII en León no hace sino reafirmar el éxito de dichas composiciones en el panorama artístico español del momento.

Palabras clave: Estampa, Johan Sadeler, Maarten de Vos, Frans Pourbus, Diócesis de Astorga.

ABSTRACT. The Flemish printer Johan Sadeler made a great number of prints inspired by the works of sevelar painters from Flanders, which were quickly spread all over Europe. Some painters and sculptors used his prints in León, especially at Astorga's bishopric, being the most popular those inspired by Maarten de Vos paintings. The great influence of these prints over some XVI and XVII century León painted and sculpted works reaffirms the success of these prints in contemporary Spanish art.

Key words: Print, Johan Sadeler, Maarten de Vos, Frans Pourbus, Astorga's diocese.
\end{abstract}

La utilización de las fuentes impresas, como inspiradoras de composiciones pictóricas, es un hecho más que probado en la historiografía artística y no pretendemos con este trabajo sino aportar algunas conclusiones más al respecto, que vayan sirviendo de referencia y de sustento al desarrollo de unos estudios consagrados y con múltiples ejemplos que sería tedioso recor- dar, por conocidos y manejados ${ }^{1}$. La elección de varias muestras en el área leonesa, en relación con el ámbito territorial de las

\footnotetext{
${ }^{1}$ Son muchos los trabajos puntuales o de carácter más global que, sobre el seguimiento de las estampas para la realización artística, se han publicado en España. Deseamos destacar únicamente la obra de B. NAVARRETE PRIETO, La pintura andaluza del siglo XVII y sus fuentes grabadas, Madrid, 1998, por lo que aporta al uso de la estampa como fuente pictórica, a través de los tratadistas y de la filosofía misma de su empleo a la hora de la valoración artística de sus resultados.
} 
diócesis de León y Astorga, fechadas en las dos últimas décadas del siglo XVI y primeros años del siglo XVII, sólo tiene como motivación dar unidad a esta puntual investigación.

Queremos insistir además en la importancia del seguimiento del grabado a la hora de valorar la creatividad del artista y de considerar la trascendencia temática, frente a la realización definitiva de la obra, amparada tan sólo en matices estéticos. La fortuna de su empleo se deja ver en la pintura, pero también en el relieve escultórico, que siempre buscó calidades pictóricas en su resultado final. Se aleja sin embargo el uso de la fuente en el caso de la escultura de bulto redondo, mucho más susceptible de mostrar la capacidad plástica del artista, al tratarse de la recreación de objetos tridimensionales y donde la estampa sólo podía servir para aportar una caracterización parcial y mucho menos detectable.

El éxito de la producción de Johan Sadeler (Bruselas 1550-Venecia 1600), el primero y más destacado miembro de toda una destacada saga de grabadores flamencos, y su inspiración en artistas de su propio ámbito geográfico, como sucede con Maarten de Vos o Frans Pourbus, excede las pretensiones de este artículo ${ }^{2}$. Las estampas de Johan Sadeler, como las que realizan también sus familiares más próximos, circulan con profusión por toda Europa y for-

\footnotetext{
${ }^{2}$ Sobre la familia Sadeler y la trascendencia de sus grabados se han escrito diferentes trabajos, algunos puntuales en relación con la trascendencia de sus imágenes, como J.M. GONZÁLEZ DE ZÁRATE Y OTROS, "Las estampas de los Sadeler como tansmisoras de modelos iconográficos en la pintura flamenca del siglo XVII", Goya, no 251, Madrid, 1996, pp. 265-275. Para el presente trabajo manejamos como referencia y apoyo a nuestros planteamientos, los repertorios clásicos de grabados: Hollstein's Dutch \& Flemish etchings, engravings and woodcuts 1450-1700 (D. DE HOOP SCHEFFER, ed.), V. XIV, Plates, I, II (1995), Text (1996), Rotterdam; The Illustrated Bartsch, 70, parts 1, 2 (Supplement), Johan Sadeler I, (by I. de Ramaix), U.S., 1999, 2001.
}

man parte del bagaje indispensable de los artistas desde los años finales del siglo XVI, de los recursos formales que era necesario manejar para responder con acierto a las peticiones de encargos.

La utilización de los grabados de generaciones anteriores de artistas, como Marcoantonio Raimondi, Bonasone, Caraglio o Beatrizet, a partir de las creaciones de los grandes maestros italianos del Renacimiento, como Rafael o Miguel Angel, sin olvidar en ningún caso la excepcional importancia de Durero, se verá considerablemente incrementada con las estampas abiertas por Sadeler partiendo de la obra de pintores flamencos de amplia repercusión. En directa relación con él tanto sus hermanos, como sus hijos y otros miembros de su familia, desarrollan un importante volumen de obra grabada que realmente invade Europa con singular fortuna en su seguimiento.

De este modo se reafirma la permanente influencia de la pintura flamenca en el arte hispano a lo largo de sucesivas centurias, desde el mismo período tardomedieval, a través de la importación y de la llegada directa de obras, para proseguir en épocas más tardías con la utilización como pauta de las fuentes impresas. El éxito de pintores como Maarten de Vos, que apenas figura en la nómina popular de los grandes pintores europeos, basado en la extraordinaria y prolífica difusión de sus composiciones por medio de la estampa, servirá para perpetuar unos particulares esquemas formales.

En las obras que tomamos como ejemplo de inspiración en las estampas publicadas por Johan Sadeler y alguno de los miembros de su familia, con secuelas en el ámbito leonés, queremos reparar en la difusión de los modelos y en los datos cronológicos que podemos destacar al respecto de los mismos. De esta manera se podrá 
advertir lo temprano de la utilización de la fuente y su éxito en el entorno en el que ahora reparamos.

\section{EL GRABADO EN LA PINTURA}

\section{a) Jerónimo de Salazar}

En la visión panorámica de los pintores asentados en Astorga en los primeros años del siglo XVII, Jerónimo de Salazar destaca por la calidad en la ejecución de algunas de sus realizaciones pictóricas frente a la mediocridad de otros artistas, que pueblan un ambiente mucho más propicio para la realización escultórica. Aunque la obra de Salazar no se ha estudiado de forma monográfica, la localización de algunos retablos suyos en la comarca gallega de Valdeorras, perteneciente a la diócesis de Astorga, sirve para probar en sus realizaciones la dependencia inspiradora de la estampa, que ya había sido apuntada en algún caso por el profesor García Iglesias³

Contratado en Astorga en 1602, con el ensamblador Claudio Xampión y el pintor Jerónimo de Salazar, el retablo de Correxais responde al esquema clasicista imperante en estos momentos, con gran protagonismo de la configuración arquitectónica y el desarrollo de un ortodoxo programa iconográfico realizado a partir de pinturas sobre tabla. Alegorías de virtudes en el banco se completan con representaciones laterales de los papas San Gregorio y San León Magno en el primer cuerpo, seguidos de San Andrés y San Sebastián en el segundo. Cuatro escenas de la infancia de Cristo,

3 J.M. GARCÍA IGLESIAS, La pintura manierista en Galicia, La Coruña, 1996, pp. 86-96. Una panorámica concreta sobre el arte en la zona de Valdeorras, incluyendo la obra de Salazar, en M.A. GONZÁLEZ GARCÍA, "El arte en Valdeorras en los siglos XVI y XVIII: la escultura y la pintura manieristas" en Cadernos do Instituto de Estudios Valdeorreses, O Barco de Valdeorras, 1993, pp. 45-62. componen el resto de la decoración pictórica del retablo. De ellas tres siguen con absoluta fidelidad estampas de Sadeler a partir de composiciones de Maarten de Vos, empleando parcialmente alguna de ellas en la cuarta.

La Adoración de los Pastores es una de las composiciones con más fortuna de Maarten de Vos a partir de la impresión en estampa publicada por Sadeler en 1582, formando parte de una serie que recogía los cinco principales artículos doctrinales de San Pablo. El juego manierista de las actitudes y la variedad de los personajes seleccionados, favoreció la difusión de la imagen y son muchos los lugares en los que se detecta el seguimiento de la misma, reducido en este caso de Correxais (Fig. 1, Fig. 2) al formato rectangular del espacio a ornamentar, del que desaparecen elementos tan curiosos y anecdóticos como el perro dispuesto en primer término ${ }^{4}$. Más parcial ha sido el uso de la estampa en el caso de la Adoración de los Magos, aprovechando el modelo grabado por Sadeler en el grupo inicial, pero jugando con la variación en el estudio en fondo de las escaleras y los personajes del segundo término.

De nuevo la relación con la fuente es totalmente coincidente en las escenas de la Circuncisión (Fig. 3, Fig. 4) y la Huida a Egipto (Fig. 6, Fig. 7), dispuestas en el segundo cuerpo, a partir del modelo sadeleriano publicado en $1581^{5}$. El pintor no hace

\footnotetext{
4 Recientemente hemos tenido oportunidad de estudiar una composición similar, conservada en el Convento de la Madre de Dios, de Olmedo (Valladolid), seguidora fiel de la estampa y fechada en 1603, lo que permite reparar en la distancia cronológica sobre la llegada del grabado a los talleres pictóricos hispanos. M. ARIAS MARTíneZ, "Adoración de los Pastores" en Clausuras. El patrimonio de los conventos de la Provincia de Valladolid. II Olmedo-Nava del Rey, Valladolid, 2001, pp. 96-97.

${ }^{5}$ Insistimos en que en ningún caso se puede olvidar la influencia imperecedera de Durero, cuyas es-
} 
más que adaptar al marco la composición inicial, sin alterarla en lo más mínimo, aunque mostrando un notable dominio del color y una soltura en la pincelada, que sirven para diferenciarlo de otros artistas que trabajan en su mismo ámbito.

Atribuidas al mismo Jerónimo de Salazar, las pinturas del retablo de Vilanova de Valdeorras ${ }^{6}$, modificado en su estructura arquitectónica en el siglo XVIII, vuelven de nuevo a responder a moldes prefijados por el seguimiento de la estampa. Utilizando fuentes diferentes a partir de diseños de Maarten de Vos en la Presentación en el Templo, como señala García Iglesias, en el caso de la Adoración de los Magos la copia literal de la estampa que publicaba Sadeler por primera vez en 1581, es un hecho innegable (Fig. 9, Fig. 10). En efecto, Salazar tomó prestada una composición seguida con éxito enorme en múltiples ejemplos del panorama de la pintura hispana de los primeros años del siglo XVII.

Por señalar algunos de ellos, con variaciones lógicas y personales en el tratamiento final, Pacheco lo empleó en una pintura para el retablo de la Virgen de Belén en la Anunciación de Sevilla ${ }^{7}$, Simón Perenys en el retablo mexicano de Huejotzingo $^{8}$ y un anónimo y discreto pintor en una tabla conservada en el Museo de Valladolid ${ }^{9}$. Son algunos de los abundantes ejemplos de la fortuna del modelo a la hora de configurar una escena tan habitual en el

tampas sirvieron de referente a generaciones de artistas. La Circuncisión de Maarten de Vos es sin duda una reinterpretación, deudora de la estampa que realizaba el artista alemán en 1505.

${ }^{6}$ J. M. GARCÍA IGLESIAS, La pintura manierista..., pp. 86-89.

7 B. Navarrete Prieto, La pintura andaluza..., pp. 121-122.

8 D. Angulo ÍñIguez, Historia del Arte Hispanoamericano, T. II, Barcelona, 1950, p. 380 y fig. 344.9 E. WATTENBERG GARCÍA (coord.), Guía colecciones. Museo de Valladolid, Valladolid, 1997, p. 193. ciclo de la Infancia de Cristo. De nuevo Salazar, en el retablo de la Asunción de Valdín, recurre reiteradamente al mismo grabado para diseñar este episodio, así como al de la Circuncisión que veíamos en Correxais, mostrando a las claras el repertorio con el que trabaja en torno al año 1600.

b) Serie de ermitaños de la Anunciada de Villafranca. Jusepe Serena

Basados en las series grabadas por Sadeler e inspiradas en Maarten de Vos, con una bibliografía precisa y estudios recientes $^{10}$, sólo queremos mencionar aquí la interesante colección de treinta escenas de ermitaños que guardan las Madres Clarisas del monasterio villafranquino de la Anunciada. Voces Jolías documentó el nombre del pintor que llevaba a cabo los trabajos por encargo del marqués de Villafranca y virrey de Nápoles, y que recibía pagos por sus trabajos en 1599.

Se trata del desconocido artista romano Jusepe Serena, que pasó al lienzo las composiciones de santos anacoretas diseñadas por de Vos, publicadas en varias y sucesivas series por las estampas de los Sadeler. Es curioso observar como algunos de los lienzos utilizan como fuente estampas impresas en 1585, mientras que otros, como en el caso que ilustramos de San Leonardo (Fig. 11, Fig, 12), toman como refe-

${ }^{10} \mathrm{~J} . \mathrm{M}^{\mathrm{a}}$ VOCES JOLÍAS, Arte religioso de El Bierzo en el siglo XVI, Ponferrada, 1987, pp. 372-378; “Lienzos de Santos Eremitas", en el catálogo de la exposición La Séptima Iglesia, Las Edades del Hombre, Astorga, 2000, pp. 81-84. Se conservan distintas series pintadas de eremitas a partir de las estampas abiertas sobre las composiciones de Marten de Vos, en las Descalzas Reales de Madrid o en el Museo Nacional de Escultura, por citar algunos ejemplos. Para estudiar la referencia de las fuentes, con las diferentes series y su publicación, Hollstein's Dutch E Flemish..., Vol. XLIV, Maarten de Vos, Text, Rotterdam, 1996, pp. 203-214. Las láminas en, Hollstein's Dutch E Flemish..., Vol. XLIV, Maarten de Vos, Plates, Part II, Rotterdam, 1995. 
rencia el Oraculum Anachoreticum, que se publicaba en Venecia en el año 1600. Se documentan pagos al artista en 1599, por lo que el conocimiento de las fuentes no puede ser más próximo en el tiempo y con seguridad las relaciones italianas del fundador y sus contactos, le permitirían acceder en instantes tan tempranos a la inspiración en las estampas, recién salidas de la imprenta y como objetos de auténtica vanguardia.

\section{c) Juan de Peñalosa}

La personalidad de Peñalosa, artista formado en círculos eruditos andaluces en relación con el pintor y tratadista cordobés Pablo de Céspedes, va a representar un considerable interés en el panorama pictórico de la Astorga del siglo XVII. Su obra como pintor y tracista, por dejar ahora a un lado su destacado papel de cronista y poeta, con brillantes manifestaciones conservadas especialmente en la catedral asturicen$\mathrm{se}^{11}$, aporta una serie de novedades y de modelos que tendrán una larga pervivencia en el arte diocesano.

Atribuido sin lugar a dudas a sus pinceles el Exvoto de la Virgen de la Majes$\operatorname{tad}^{12}$, que se coloca en uno de los laterales de su capilla, supone la vista más primitiva de la ciudad conocida hasta el momento. A

${ }^{11}$ F. LlamaZAReS "Juan de Peñalosa y Sandoval. Testamento, muerte y almoneda", Tierras de León, no 41, León, 1980, pp. 89-96. Sobre la actividad de Peñalosa en Astorga, M.A. GonZÁlez GarCía “D. Alonso Mexía de Tovar: apuntes sobre un obispo mecenas en el primer tercio del siglo XVII", Actas del VII Congreso Español de Historia del Arte (1988), Murcia, 1992, pp. 421-430; J. de PEÑAlOSA y SANDOVAL, Relación de las fiestas que celebraron en la ciudad de Astorga... 1626, (Transcripción y edición B. VELADO GRAÑA), Astorga, 1996.

12 M.A. GonZÁLeZ GARCíA, “Milagro de Nuestra Señora de la Majestad", en el catálogo de la exposición La Séptima Iglesia, Las Edades del Hombre, Astorga, 2000, pp. 95-96. su consideración formal hay que añadir el valor de crónica de la vida urbana que en si mismo representa. Con la narración de una procesión de acción de gracias que había tenido lugar en la ciudad en el siglo XV, Peñalosa traslada y contextualiza su desarrollo a los primeros años del siglo XVII, concretamente a 1622, cuando lleva a cabo la pintura del lienzo. Los personajes que se muestran, el obispo, los capitulares y el regimiento de la ciudad, son de este modo retratos fidedignos de quienes detentaban las principales magistraturas de la urbe, para los que difícilmente podía utilizar estampas en las que basar su pintura.

Es en un detalle de la composición del lienzo, en las dos figuras que se colocan en el lateral inferior izquierdo del espectador, donde el pintor iba a utilizar como fuente de inspiración un fragmento de la escena de la Degollación de San Pablo, grabada por Johan Sadeler en 1580 y basada en una composición perdida del pintor flamenco Frans Pourbus, sobre la vida del apóstol (Fig. 13, Fig. 14). Peñalosa resuelve con la incorporación de estas dos figuras, el cierre lateral del cuadro, invirtiendo su disposición en la estampa. La difícil postura del personaje que se coloca de espaldas a la visión del cuadro, su compleja torsión y la desnudez de la espalda han sido proporcionados por los recursos que ofrece la fuente impresa. Se trata de un ejemplo de utilización parcial y mesurada de la fuente para resolver una composición ${ }^{13}$, que proporciona una idea de la calidad misma del autor. Esta actitud se detecta en otras obras de su producción conservadas en Astorga,

\footnotetext{
${ }^{13}$ En la almoneda de Peñalosa se rematan en el pintor Juan de Saldaña "los papeles de estampas de pintu$r a^{\prime \prime}$ en 24 reales, sin que se aporten más datos sobre el contenido de estas imágenes impresas. F. Llamazares, Op. Cit., p. 96.
} 
expresión de la creatividad y la preparación de un pintor erudito ${ }^{14}$.

\section{d) Cuadros del Museo de León con la Historia de Santiago Apóstol}

Procedentes de la casa santiaguista de San Marcos ${ }^{15}$, conserva el Museo de León tres lienzos con episodios destacados de la vida de Santiago el Mayor, aunque en origen se presupone que la serie fuera más completa, sin que se haya podido hacer atribución de la misma a maestro conocido alguno. De los tres lienzos conservados, el primero de ellos, con la narración del episodio de la vocación de los apóstoles en la barca de Pedro, es el que se sitúa en el primer lugar de la secuencia cronológica de los acontecimientos. La escena transcurre en el paisaje recreado del lago de Genesaret, siguiendo en sus líneas generales la composición invertida de Rafael Sanzio para uno de los tapices destinados a la Capilla Sixti-

-

${ }^{14}$ La inspiración de otros trabajos, imprimiendo a su creación un carácter propio, se puede observar en el Juicio Final conservado en el Museo de la Catedral de Astorga, que con buen criterio se ha atribuido a su mano. Además de la siempre presente imagen miguelangelesca de la Sixtina, Peñalosa hace su interpretación particular siguiendo la huella de su entorno formador, sin olvidar la trascendencia de la estampa a través de los Juicios pintados por Maarten de Vos. Además, la deuda compositiva es innegable, a partir del Jucio Final que pintara Pacheco para Santa Isabel de Sevilla en 1614, ahora conservado en el Museo Goya de Castres (Francia). E. VALDIVIESO y J. M. SERRERA, Pintura sevillana del primer tercio del siglo XVII, Madrid, 1985, p. 79, lam. 25. El interés de la composición astorgana de Peñalosa se singulariza con la incorporación de Dante Alighieri entre las figuras de los condenados.

15 Ma C. GONZÁlez CHAO, Catálogo de Pinturas. Museo de León, León, 1995, pp. 22-23. Los lienzos miden 150x148 c. En el mismo convento de San Marcos se conservan otros ejemplos evidentes del seguimiento de la estampa en el instante de pintar una serie de lienzos, como se muestra en el célebre apostolado del retablo mayor, a partir de las populares composiciones de Goltzius. Agradezco a Luis Grau, director del Museo de León y amigo, haberme facilitado las fotografías que ilustran estos cuadros. na, realizado entre los años 1514-1515, con el tema de la Pesca Milagrosa (Fig. 15).

Conservado el cartón realizado por Rafael para esta composición en el Museo Victoria and Albert de Londres, sólo conocemos una interpretación impresa de la misma, la xilografía al claroscuro abierta por Ugo da Carpi ${ }^{16}$ (Fig. 16). Parece que esta fue la fuente empleada, por ejemplo, por Jacopo Bassano para su versión de la Pesca Milagrosa, realizada en 1545 y conservada en la National Gallery de Washington ${ }^{17}$. Es probable que la estampa de Carpi permitiera el conocimiento de la composición al anónimo artista encargado de llevar a cabo esta serie para el convento de San Marcos de León. No obstante, no se puede descartar que la fuente no se transmitiera en este caso a través del grabado sino de un tapiz inspirado en los cartones de Rafael. En 1517 ya estaban realizados los primeros tapices de la serie en Bruselas, en el taller de Pieter van Aelts con destino a la Capilla Sixtina, pero a partir de aquí se tejieron otras muchas series empleando como motivos los diseñados por Rafael. Este hecho, unido a la inversión compositiva, motivada por una razón previamente conocida por el artista ${ }^{18}$, podrían hacernos pensar en este sistema de difusión, más que en la tradicional estampa.

El grupo inicial, el de la primera barca en la que Cristo bendice a San Pedro, arrodillado ante el Maestro y seguido de su

16 The Illustrated Barstch, 48 (Formerly volume 12) Italian chiaroscuro woodcuts (Ed. by C. KARPINSKI), New York, 1983, pp. 38,39.

${ }^{17}$ Aunque Sadeler grabará en Venecia al final de su vida, obras de los Bassano, no encontramos en su catálogo ninguna referencia a la Pesca Milagrosa de 1545. Por otra parte, Jacopo Bassano interpreta con destacadas aportaciones la composición original, especialmente a la hora de configurar las vestiduras del personaje de San Andrés.

18 Rafael realizó los cartones a la inversa de cómo resultarían en el tapiz, pues el resultado de la manufactura imponía ese método de trabajo. 
hermano Andrés, reproducen con fidelidad la escena rafaelesca(Fig. 17). Una vez más la disposición del apóstol Andrés, con los brazos abiertos y en atrevido escorzo, está haciendo referencia a alardes compositivos como los ensayados por Miguel Angel en su famosa Batalla de Cascina, de 1504, que muy pronto se están difundiendo fuera de Italia ${ }^{19}$.

Sin embargo el anónimo maestro de los lienzos leoneses, abandona su fuente de inspiración a la hora de interpretar a dos de los tres personajes de la segunda barca. Las figuras de Rafael, que en la composición original aparecen ejecutando un enorme esfuerzo para sacar la red cargada de pesca, mostrando la fortaleza anatómica de los brazos y el atrevimiento de una compleja disposición, aparecen de pie en el lienzo. Naturalmente se trata de proporcionar un mayor protagonismo a los hermanos Santiago y Juan, dentro de la historia del primero, presentes en el episodio milagroso, pero reducidos en su protagonismo por los pinceles de Rafael, quien destacaba en su serie de tapices la personalidad de Pedro. En esta ocasión el pintor debía convertir en actor principal al apóstol Santiago, de manera que no le servía la disposición en que Rafael había concebido la escena.

El seguimiento directo de las fuentes, en este caso ya inspirado en las exitosas estampas de Sadeler y a partir de las composiciones originales de Maarten de Vos, se aprecia con absoluta claridad en los dos lienzos que completan el conjunto. En el caso de la Predicación de Santiago, el artista

\footnotetext{
${ }^{19}$ Esto se manifiesta en la actitud de San José en el Nacimiento de Cristo pintado por Alonso Berruguete, para el retablo de San Benito el Real de Valladolid, ahora en el Museo Nacional de Escultura, a finales del primer cuarto del siglo XVI. Al respecto de la difusión de lo que supone este catálogo de actitudes, A. AvILA, "Repercusión de la Batalla de Cascina en la pintura española del primer Renacimiento", Goya, no 190 , Madrid, 1986, pp. 194-201.
}

ha empleado literalmente la escena de la Predicación de San Sebaldo, que forma parte de la serie pintada por de Vos para su Trophaeum vitae solitariae ${ }^{20}$, grabada por Johan y Raphael Sadeler y publicada en Venecia en 1598 (Fig. 18, Fig. 19). Sebaldo de Nuremberg es un santo que aparece en la iconografía vistiendo hábito de peregrino, con capa y bordón ${ }^{21}$. De familia noble y casado con una princesa de Francia, abandonó a su esposa para peregrinar a Roma y en esta actitud, predicando en un claro del bosque, con la vista de la ciudad de $\mathrm{Nu}-$ remberg al fondo, donde se custodian sus restos, aparece en la composición grabada por los Sadeler. Naturalmente la inspiración de Maarten de Vos tiene que partir de alguna de las numerosas predicaciones de Juan el Bautista, una escena habitual en el ciclo iconográfico del santo y con seguridad punto de referencia empleado por el artista.

El anónimo artista de los lienzos leoneses, adaptó la temática convirtiendo a Sebaldo en Santiago apóstol, sin modificar apenas las líneas originales que le ofrecía la estampa. Los personajes principales que componen la escena siguen con detalle la fuente impresa y tan sólo el paisaje urbano original se transforma en un fondo natural. La fortuna de las series de ermitaños y anacoretas diseñadas por Maarten de Vos y grabadas en su primera versión por Sadeler, fue más que notable y superó la reproducción de las mismas para confeccionar series referidas al mismo tema, como después comprobaremos. La fecha de la impresión de la primera serie en 1594, sirve como pauta cronológica relativa a la hora de datar los lienzos leoneses en los primeros años del siglo XVII más que en los últimos del

${ }^{20}$ Hollstein's Dutch \& Flemish..., Vol. XLIV, Maarten de Vos, Text, Rotterdam, 1996, pp. 209-212.

${ }^{21}$ L. RÉAU, Iconografía del arte cristiano. Iconografía de los santos (De la P a la Z. Repertorios)T.2, v. 5, Barcelona, 1998, pp. 192-193. 
XVI, a causa de la propia difusión de la estampa.

El tercero de los lienzos, el que representa la degollación de Santiago, vuelve de nuevo a ser replica exacta de la misma escena, a partir de un dibujo perdido de Maarten de Vos, en esta ocasión formando parte de una serie grabada por Johan Sadeler sobre los Hechos de los Apóstoles, hacia 1580 (Fig. 20, Fig. 21). El catálogo de disposiciones de los personajes que componen el episodio está tomado al pie de la letra de la fuente original. Esto se observa desde la colocación del protagonista centrado en un segundo plano, hasta la posición indolente del rey Herodes, que presencia el martirio cruel de la decapitación sin inmutarse. Las arquitecturas del fondo son idénticas a las de la estampa y la composición no ha sufrido mayores innovaciones, con la supresión de algunos personajes secundarios que harían demasiado compleja la disposición abigarrada del grupo.

\section{II) EL REFLEJO DE LA ESTAMPA EN LA ESCULTURA}

a) Retablo de Bercianos de Vidriales. Bartolomé Hernández

La reivindicación de la figura de Bartolomé Hernández en el panorama escultórico leonés de los últimos años del siglo XVI, toma cierto carácter con el paulatino conocimiento de sus obras y su trayectoria formativa al lado de Gaspar Becerra, y en contacto con las novedades estéticas que se producían en la corte. Sin entrar en mayores detalles, sólo pretendemos ilustrar el uso de las fuentes impresas en alguna de sus realizaciones, después de su regreso y asentamiento en Astorga tras el fallecimiento de su maestro en 1568. El retablo mayor de la iglesia parroquial de Bercianos de Vidriales supone, al lado de otros conjuntos diseñados por el artista, la consagración del modelo ideado por Becerra y revoluciona- rio en la retablística hispana ${ }^{22}$. El retablo de Bercianos, tasado en 1591, tuvo que ser encargado en la década anterior, posiblemente en torno a 1585.

A la hora de analizar la composición iconográfica y estilística de los relieves, es muy interesante la inspiración en las estampas de Sadeler, elegidas en primer lugar para llevar a cabo composiciones inexistentes en el retablo mayor de la catedral de Astorga, catálogo inexcusable de formas de este periodo. Así la inexistencia del relieve que muestra la Huida a Egipto obligó al escultor a buscar una fuente, que encontraría en el grabado de Sadeler, seguido con absoluto detalle, sin apartarse en lo más mínimo de la información gráfica original (Fig. 6, Fig. 8) y que, como hemos visto en la pintura, también había sido utilizado en otras obras del entorno.

En otro caso, Hernández va a utilizar la estampa en relación con la conveniencia de apartarse de los modelos de Becerra en el retablo de la catedral ${ }^{23}$. Esto es lo que sucede con la representación del episodio de Jesús entre los doctores. La torpeza de este relieve en su tratamiento general, dentro de la enorme y bien compuesta máquina del retablo astorgano, es evidente. En esta situación, para atender al encargo de Bercianos, el escultor toma parcialmente otra de las estampas de Sadeler que, sin embargo no va a resolver finalmente con demasiada fortuna (Fig. 22, Fig. 23). No se han proporcionado los volúmenes con respecto a la fuente y todo lo airoso de la com-

\footnotetext{
${ }^{22}$ M. A. GONZÁlez GARcíA, “El retablo mayor de Bercianos de Vidriales", Astórica, nº 1, Astorga, 1983, pp. 99-118. Algunas de las fotografías que sirven para ilustrar estos ejemplos escultóricos, están tomadas de Inventario de bienes muebles de la Diócesis de Astorga, a cuyos responsables queremos mostrar nuestro agradecimiento.

${ }^{23}$ M. ARIAS (coord.), El retablo mayor de la catedral de Astorga. Historia y Restauración, Valladolid, 2001.
} 
posición original, se ve aquí transformado hacia una acumulación desorganizada y mal resuelta, más preocupada por la transmisión iconográfica que por los aspectos formales.

Los dos grabados que aquí señalamos como ejemplo, fueron impresos por primera vez en Colonia por Johan Sadeler. La escena de la Huida a Egipto está fechada como ya vimos en 1581, mientras que la de la Jesús entre los doctores, se data en 1582. La tasación del retablo en 1591, que supone su terminación completa tanto de talla como de policromía, permite acercarnos a la rápida llegada de las estampas y su pronta utilización por el artista al servicio de esquemas formales sugerentes y novedosos, en el panorama periférico en el que desarrollaba su trabajo.

El uso de los repertorios grabados es evidente en la concepción del apostolado dispuesto en los netos del retablo, aunque en esta ocasión Hernández no ha manejado estampas impresas por Sadeler, pero sí diseños del repetidamente citado Maarten de Vos. El apostolado del pintor flamenco serviría de base para diferentes series impresas con ligeras variaciones en cuanto al resultado final. Una de ellas, posiblemente la más temprana, fue la que grabó y publicó Hieronymus Wierix en 1578, sin duda la procedencia de los apóstoles de Bercianos ${ }^{24}$. $\mathrm{Su}$ seguimiento manifiesta una gran fidelidad con la idea ofrecida y es expresión del deseo de reflejar con todo cuidado una caracterización iconográfica inequívoca de los personajes (Fig. 25, Fig. 26). Se trataba de algo que Becerra no había logrado plenamente en su apostolado del retablo de Astorga, muchos de cuyos componentes no

\footnotetext{
24 En 1592, Adriaen Collaert publica otra serie sobre el apostolado de Maarten de Vos, demasiado tardía para las fechas del retablo de Bercianos. Hollstein's Dutch \& Flemish..., Vol. XLIV, Maarten de Vos, Text, Rotterdam, 1996, pp. 176-178, 183-185.
}

portan atributos que los diferencien con claridad, por lo que posiblemente Hernández desecharía la opción de tomarlo como pauta.

b) Retablo de la Visitación de Granucillo de Vidriales.

Se conserva en la iglesia parroquial de Granucillo un retablo de rasgos formales netamente romanistas. Modificado en su concepción original por transformaciones posteriores, la configuración del mismo nos lleva a fecharlo en el primer cuarto del siglo XVII. La estructura arquitectónica, con frontones partidos, pirámides y las propias soluciones de la policromía, parecen datarlo en época posterior a la actividad de Bartolomé Hernández. Sin embargo el escultor aparece documentado trabajando en un retablo de esta misma parroquia, por el que recibe pagos recién vuelto de su etapa madrileña, a las órdenes de Gaspar Becerra ${ }^{25}$, entre los años 1568 y 1572.

Las representaciones pareadas de apóstoles en el banco recuerdan mucho su modo de trabajar, como el uso de las columnas decoradas en el tercio bajo o como el relieve de la Visitación dispuesto en la parte superior, que sigue con bastante fidelidad una estampa de Johan Sadeler basada en de Vos, impresa en Colonia y fechada en 1582. La fecha de la estampa no encaja con la documentación sobre el retablo, aunque es probable que lo único que esto quiera decir es que el trabajo de Hernández no se concluyó en su momento. Es posible que el escultor siguiera trabajando para el retablo después de las fechas indicadas, al tiempo que lo hacía en otras localidades del entorno, como hemos visto en Bercianos. Además el Libro de Fábrica de la iglesia de Santa María de Granucillo se interrumpe en 1612, por lo que la configuración final del

\footnotetext{
${ }^{25}$ M. ARIAS (coord.), El retablo mayor...
} 
retablo pudo realizarse a partir de esos instantes, como demuestra la misma decoración del conjunto.

Una vez más el relieve es deudor de la estampa (Fig. 27, Fig. 28). Los dos grupos que componen la escena están tomados de la fuente con ligeras licencias de disposición. Isabel y María se colocan en primer plano, centrando el contenido del mensaje. La imagen de María reproduce la de la estampa, mientras que la figura de Isabel pierde la disposición frontal buscando una actitud de diçalogo más comprensible. Mientras, en la parte posterior del relieve, se desarrolla el saludo cortés entre José y Zacarías, cambiados de ubicación por una mera adpatación al marco. De nuevo el episodio narrado no se encontraba accesible en el "catálogo" elaborado por Becerra en el retablo catedralicio y el escultor emplea los recursos que Sadeler le proporciona.

\section{c) Retablo de Nogarejas. Gregorio Es- pañol}

Tampoco es este el instante de reparar en la trayectoria profesional del escultor astorgano Gregorio Español (+1631), una de las figuras más destacas de la plástica en el ámbito en el que ahora nos detenemos ${ }^{26}$. $\mathrm{Al}$ igual que estamos haciendo con otros escultores o pintores, se pretende tan solo utilizar alguna de sus obras como ejemplo de la influencia de las fuentes impresas a la hora de concebir la traza de sus composiciones. Nos fijamos en esta ocasión en un relieve del desaparecido retablo de Nogarejas ${ }^{27}$,

-

${ }^{26}$ F. LLAMAZARES “Gregorio Español, un escultor leonés desconocido", Tierras de León, León, 1981, no 42. M. A. GonZÁlez GARCíA, La obra del escultor Gregorio Español en tres arciprestazgos de la Diócesis de Astorga, Tesis de licenciatura inédita, Santiago de Compostela, 1984.

${ }^{27}$ F. LLAMAZARES, El retablo barroco en la provincia de León, León, 1991, pp. 159-162. M.A. González García "El retablo mayor de Nogarejas, una obra expoliada tasado en 1610, como ejemplo de este habitual proceso.

El relieve del Martirio de San Lorenzo, directamente inspirado en Tiziano a través de estampas bien de Aegidius Sadeler, bien de Cornelis Cort, pues ambos abrieron estampa del mismo tema ${ }^{28}$, es ahora motivo de nuestra curiosidad. La desigualdad del relieve respecto a otras obras de Español, incluso dentro del mismo retablo, que ya señala Miguel Angel González, lleva más hacia una obra de taller que a un trabajo salido de las gubias del propio maestro (Fig. 29, Fig. 30). El grupo del martirio, en primer término, con los dos verdugos que atizan el fuego y sujetan al santo a la parrilla, es una interpretación literal de la composición tizianesca, que el colaborador de Español lleva a cabo sin saber resolver los problemas de perspectiva generados por la particular lectura de una estampa compleja.

d) Retablo de Huerga de Garaballes. Pedro de Villaba y Juan de Usinaga

Con una azarosa historia, el retablo de Huerga de Garaballes se inicia en 1578, tras un contrato firmado con el entallador Pedro de Villaba ${ }^{29}$. El fallecimiento de Villaba en 1594 obligó a que la parroquia contratara al escultor asentado en Astorga, Juan de Usinaga, para que terminara los trabajos, tarea que había cumplido antes de 1603, cuando dicta su testamento. Se trata de un retablo de concepción romanista, siguiendo los moldes que se perpetuaban en la diócesis astorgana, después de la obra catedralicia de Becerra.

del escultor Gregorio Español", Tierras de León, León, 1994, no 95-96. El retablo fue robado en el año 1987.

28 The Illustrated Bartsch, 52, Netherlandish Artists. Cornelis Cort, (Ed. by Walter L. STRAUSS and T. SHIMURA), New York, 1986, pp. 162-164.

${ }^{29}$ F. LLAMAZARES, El retablo barroco..., pp. 146-149. 
Naturalmente la secuela del retablo catedralicio, como fue habitual, se observa en el tratamiento escultórico. El Relieve de Jesús entre los Doctores, en la figura del Niño dispuesto en el centro de la narración y en actitud mayestática, es émulo directo de la composición diseñada por Becerra. Sin embargo en el resto de los personajes que componen el grupo, el autor utiliza la conocida estampa de Sadeler a partir del dibujo de Maarten de Vos, aunque realizando una lectura libre de la misma (Fig. 22, Fig. 24), con referencias innegables a la fuente impresa como la colocación de la Virgen al lado de la figura de su hijo o la disposición del propio sombrero de San José, que ha aumentado considerablemente de tamaño.

e) Retablo de Nuestra Señora de la Encina de Ponferrada

Con una larga historia documental, que se inicia en 1630 y con la participación de un elevado número de artistas, el retablo mayor de la basílica de Nuestra Señora de la Encina, en Ponferrada, es uno de los conjuntos retablísticos más importantes de nuestro entorno. A un anónimo escultor, que trabajaría en compañía de Jácome y Mateo de Prado, atribuye Fernando Llamazares los relieves de la Adoración de los Pastores y de la Circuncisión ${ }^{30}$.

Queremos detenernos para finalizar, en este último, salido de la gubia de un escultor, "poco dotado" como afirma el propio Llamazares y según observamos ahora, deudor de los préstamos que le suministraba la estampa, interpretados con torpeza (Fig. 3, Fig. 5). Una vez más es el grabado de la Circuncisión que Sadeler imprime en 1581, el utilizado como referente, reinterpretado con poca habilidad, pero siguiendo sin duda la pauta marcada por la fuente.

\footnotetext{
${ }^{30}$ Ibidem, pp. 118-134.
} 

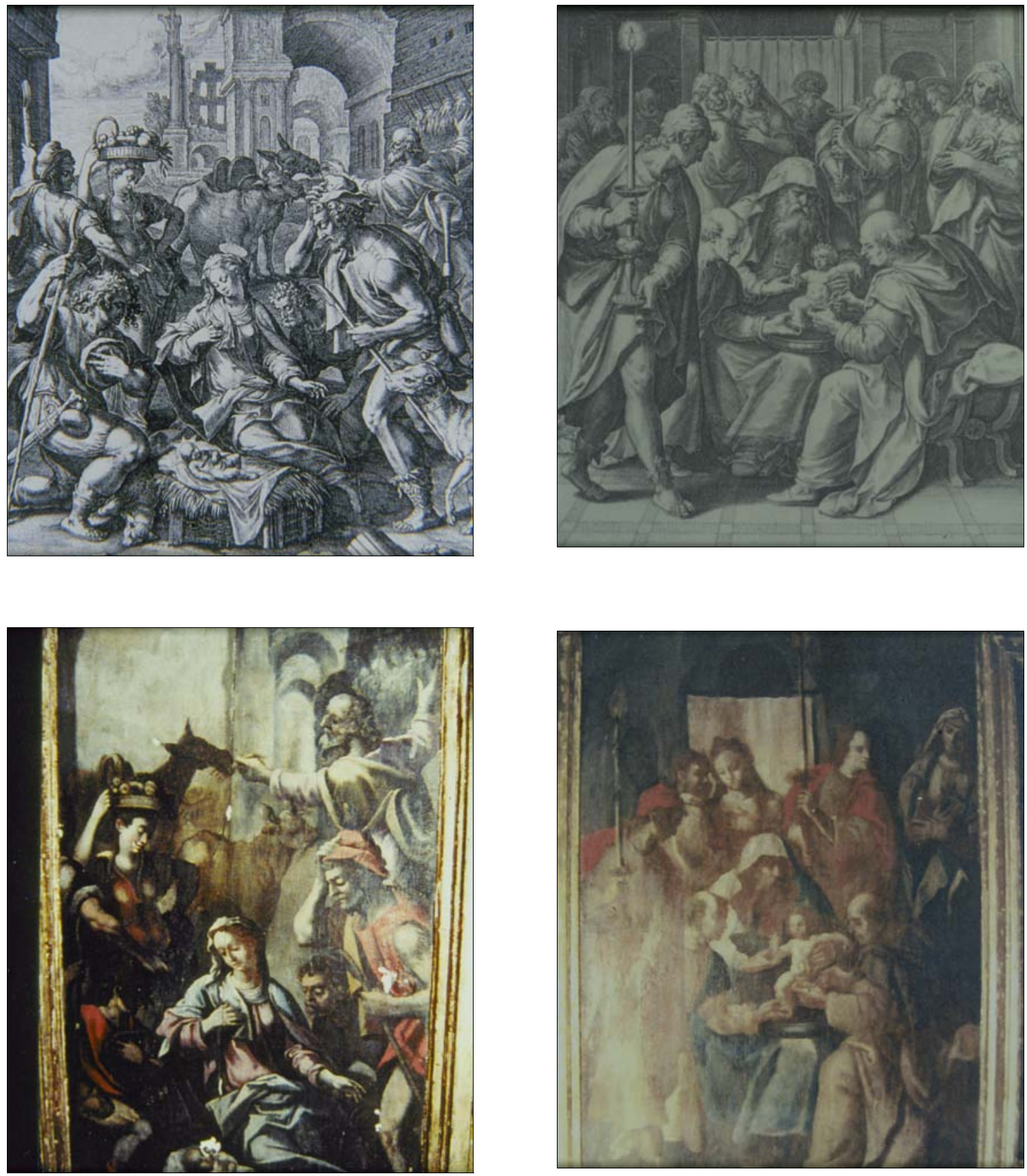

- Fig.1. Adoración de los Pastores. Estampa de Johan Sadeler a partir de Maarten de Vos. 1582

(arriba izda)

- Fig.2. Adoración de los Pastores. Jerónimo de Salazar. Retablo mayor de Correxais. 1602

(abajo izda)

- Fig.3. Circuncisión. Estampa de Johan Sadeler a partir de Maarten de Vos. 1581 (arriba dcha)

- Fig.4. Circuncisión. Jerónimo de Salazar. Retablo mayor de Correxais. 1602 (abajo dcha) 

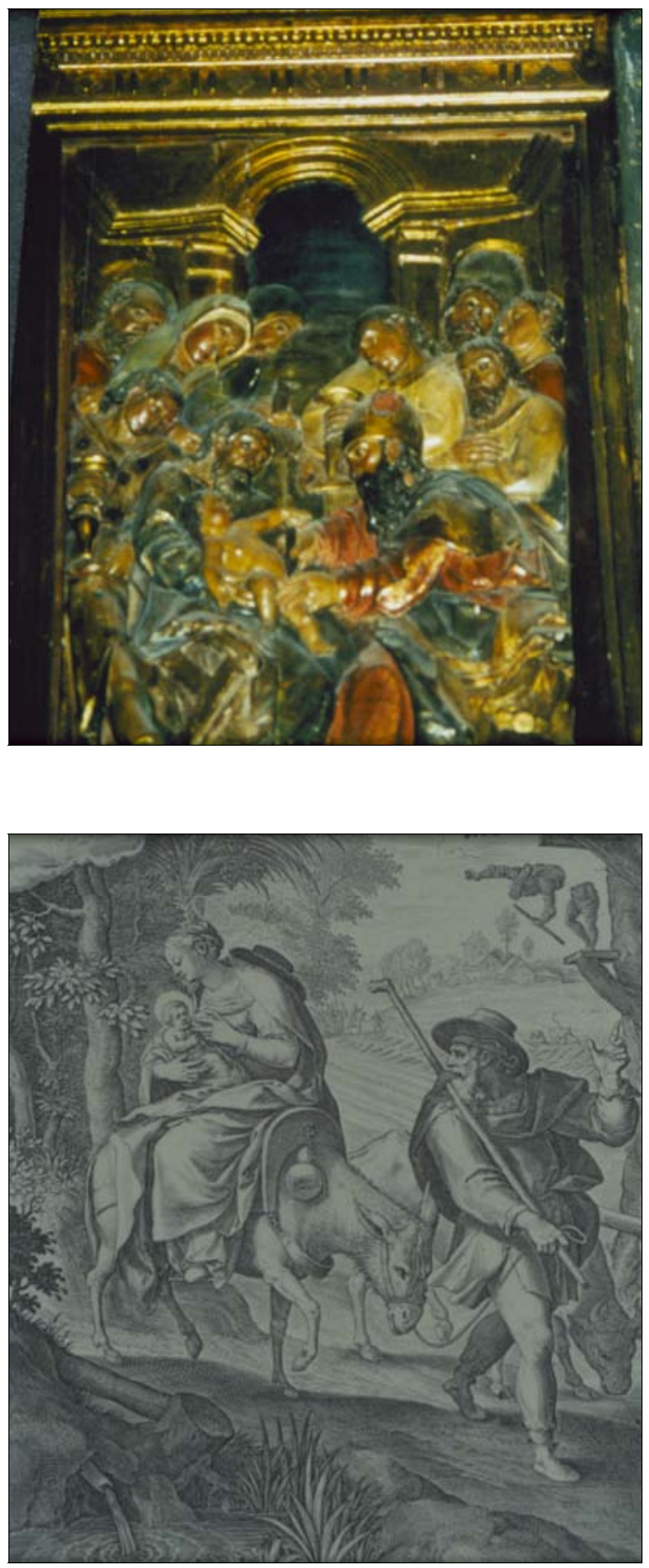

- Fig.5. Circuncisión. Anónimo. Retablo mayor de Nuestra Señora de la Encina, Ponferrada. Hacia 1630. (arriba izda)

- Fig.6. Huida a Egipto. Estampa de Johan Sadeler a partir de Maarten de Vos. 1581.

(abajo izda)
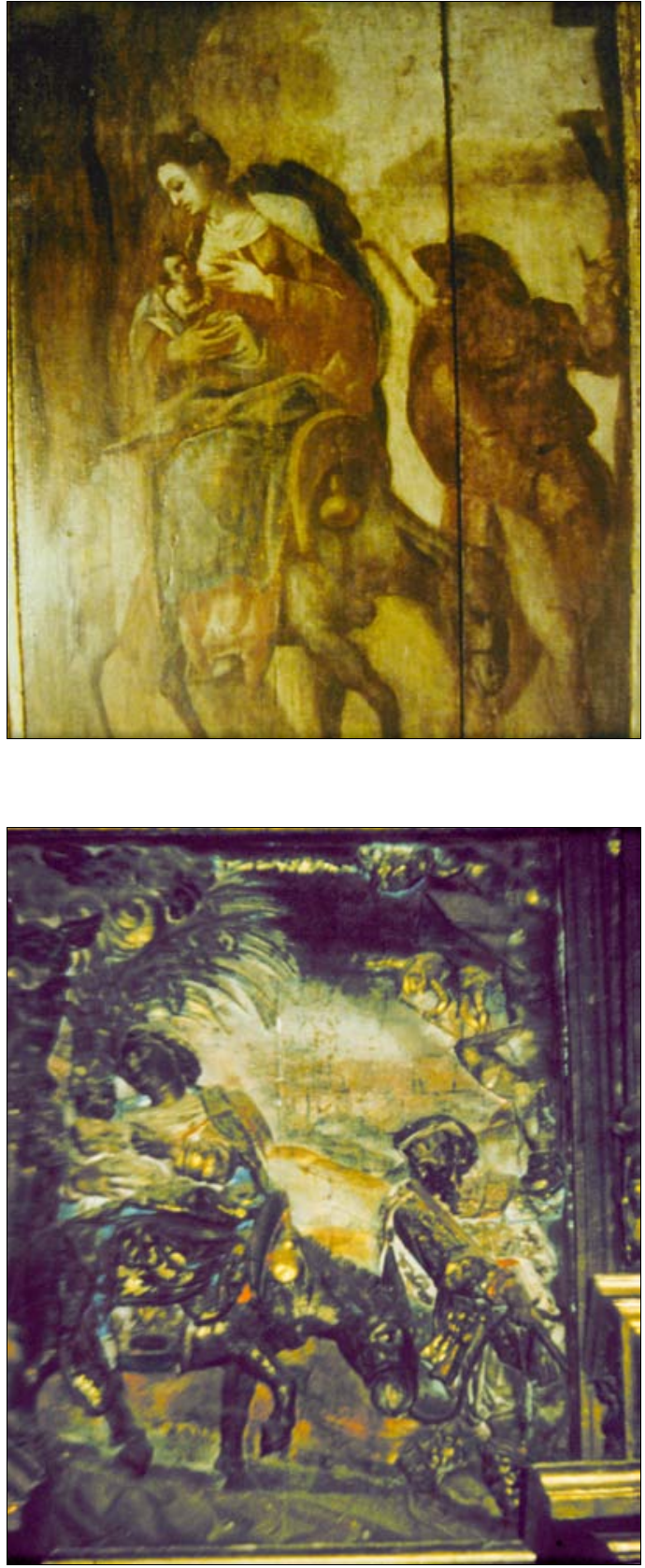

- Fig.7. Huida a Egipto. Jerónimo de Salazar. Retablo mayor de Correxais. 1602. (arriba dcha)

- Fig.8. Huida a Egipto. Bartolomé Hernández. Retablo mayor de Bercianos de Vidriales. Tasado en 1591.

(abajo dcha) 

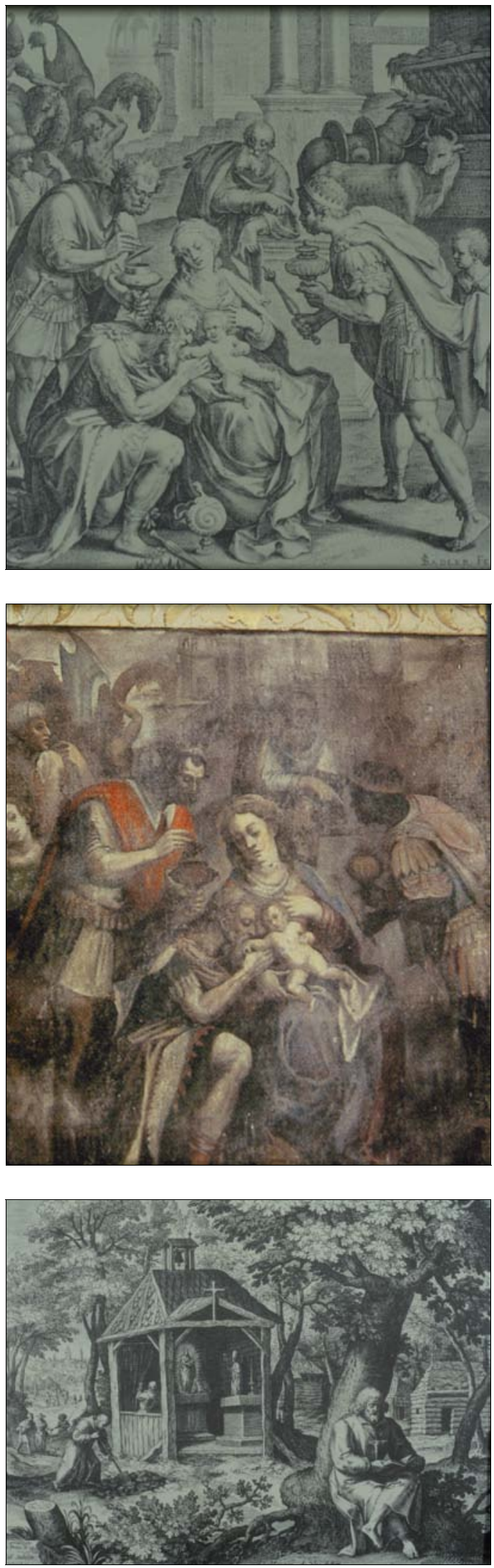
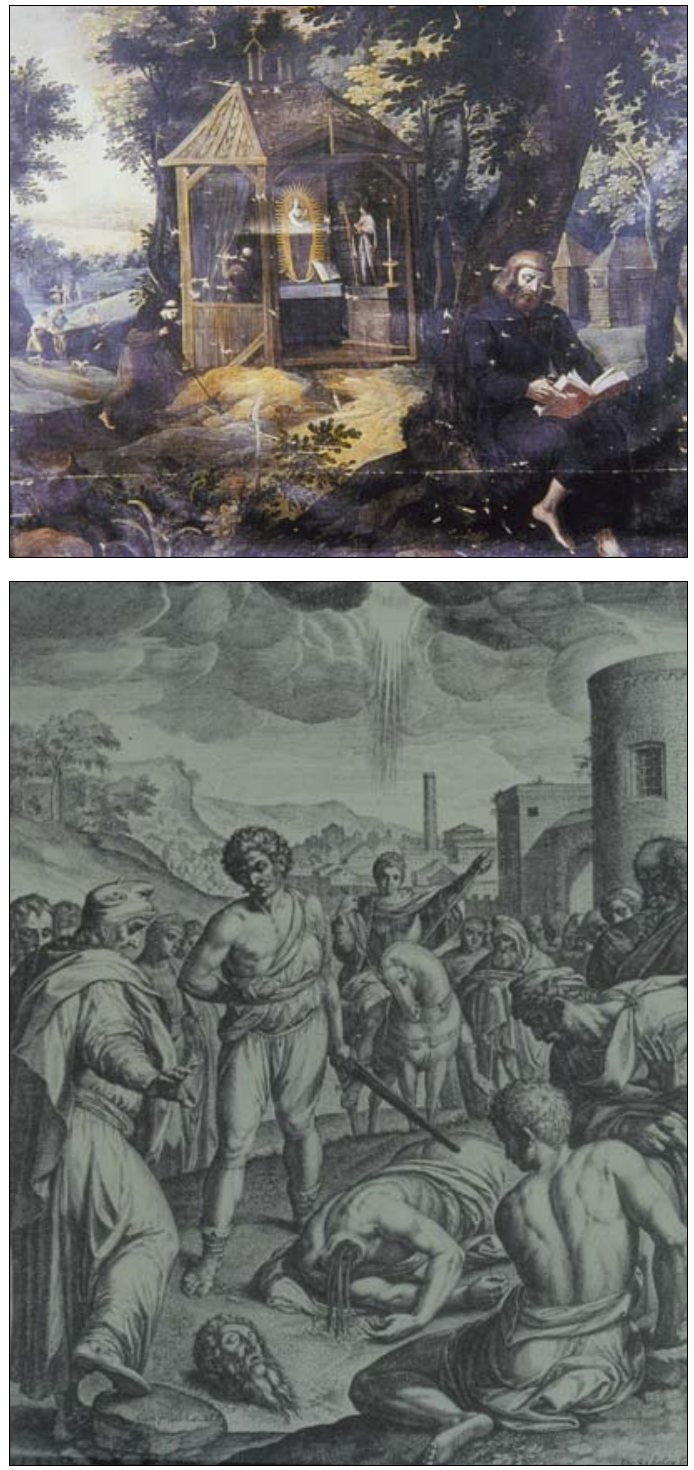

- Fig.9. Ad. de los Magos. Est. de J. Sadeler a p. de M. de Vos. 1581 (arriba izda)

- Fig.10. Adoración de los Magos. Jerónimo de Salazar. Retablo mayor de Vilanova de Valdeorras. C. 1600. (centro izda)

- Fig.11. S. Leonardo. Est. de J. Sadeler a partir de M. de Vos en el Oraculum Anachoreticum, Venecia, 1600 (abajo izda)

- Fig.12. San Leonardo. Jusepe Serena. Monasterio de la Anunciada. Villafranca del Bierzo. C. 1600. (arriba dcha)

- Fig.13. Degollación de San Pablo. Estampa de Johan Sadeler a partir de Frans Pourbus. 1580. (centro dcha) 

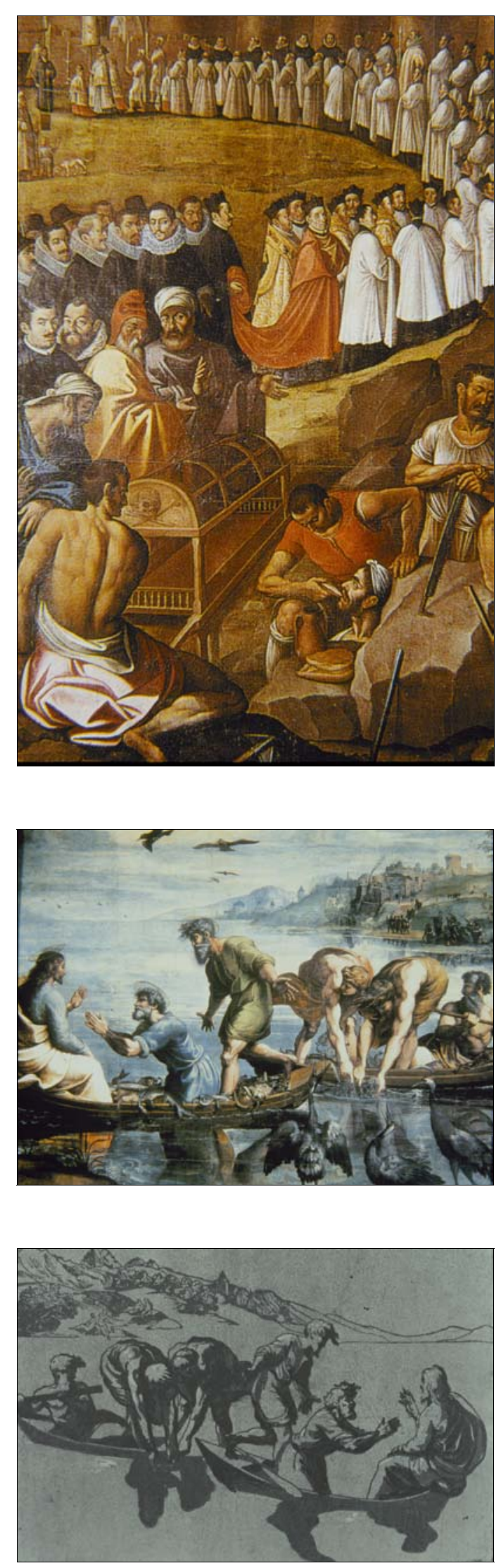
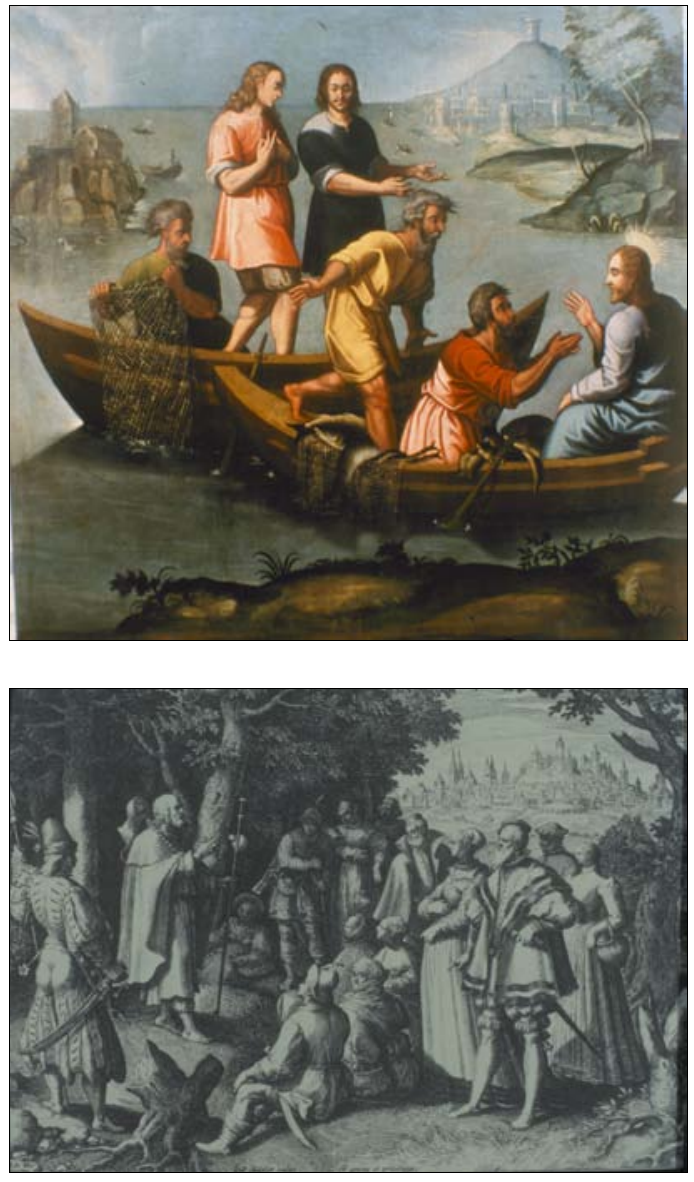

- Fig.14. Detalle del Exvoto a la Virgen de la Majestad. Juan de Peñalosa. Catedral de Astorga. 1622 (arriba izda)

- Fig.15. Cartón preparatorio para el tapiz de la Pesca Milagrosa. Rafael Sanzio. Museo Victoria and Albert. 1514-1515 (centro izda)

- Fig.16. La Pesca Milagrosa. Xilografía al claroscuro de Ugo da Carpi, a partir de Rafael. Segundo tercio del siglo XVI (abajo izda)

- Fig.17. La vocación de los Apóstoles en la barca de San Pedro. Anónimo. Museo de León. Primer cuarto del siglo XVII (arriba dcha)

- Fig.18. Predicación de San Sebaldo. Estampa de Johan y Raphael Sadeler a partir de Maarten de Vos en el Trophaeum Vitae Solitariae, Venecia, 1598 (centro dcha) 

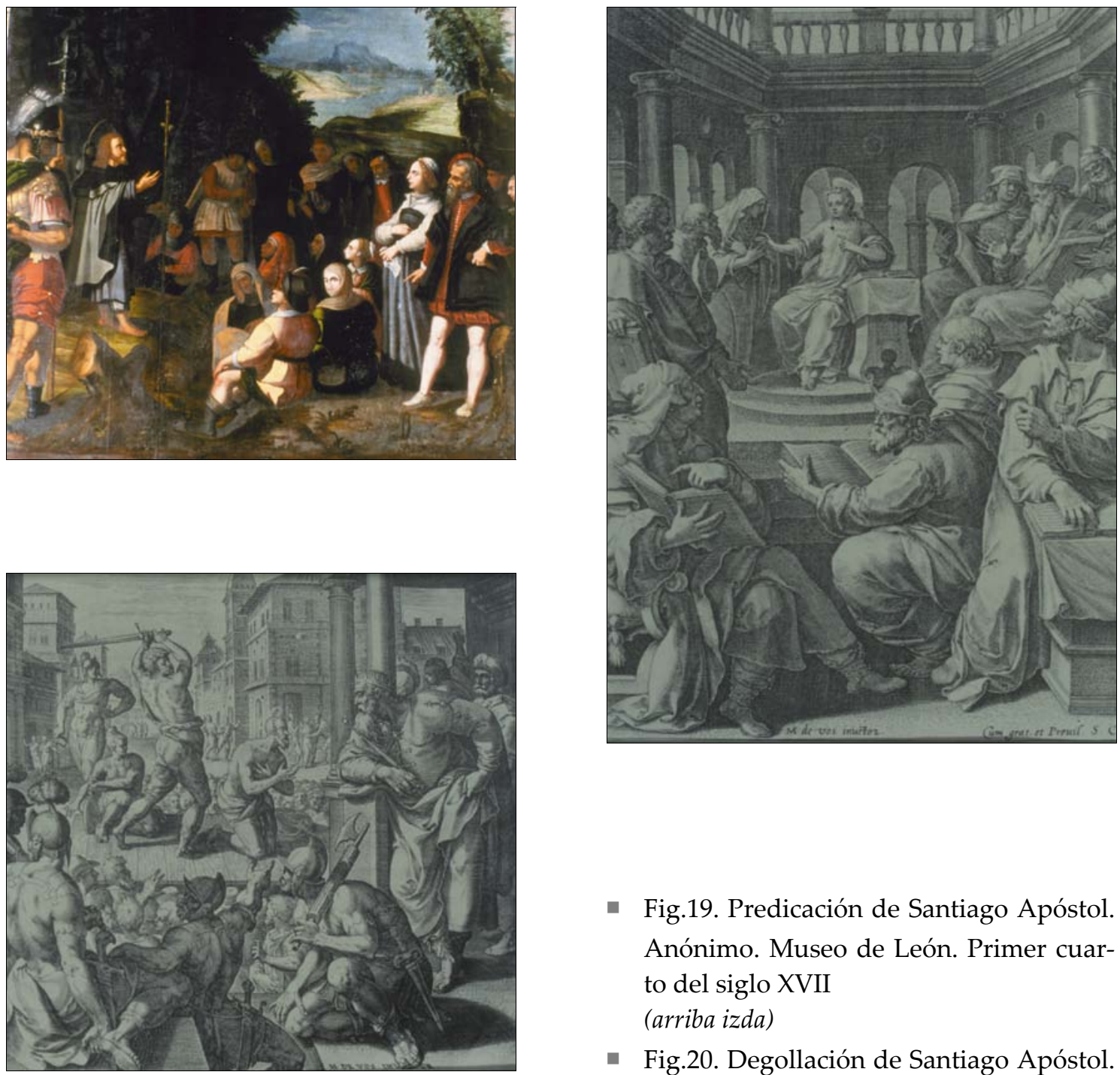

- Fig.19. Predicación de Santiago Apóstol. Anónimo. Museo de León. Primer cuarto del siglo XVII (arriba izda)

- Fig.20. Degollación de Santiago Apóstol. Estampa de Johan Sadeler a partir de Maarten de Vos en una serie sobre los

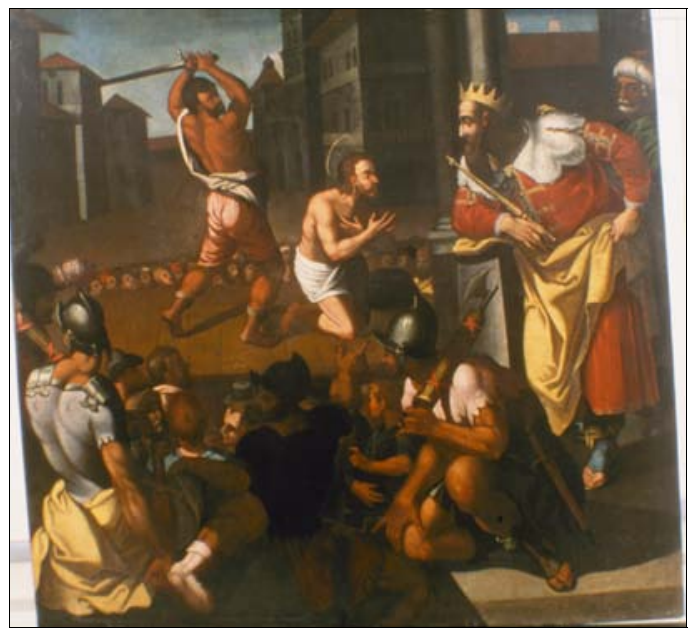
Hechos de los Apóstoles. C. 1580 (centro izda)

- Fig.21. Degollación de Santiago Apóstol. Anónimo. Museo de León. Primer cuarto del siglo XVII (abajo izda)

- Fig.22. Jesús entre los Doctores. Estampa de Johan Sadeler a partir de Maarten de Vos. 1582 (arriba dcha) 

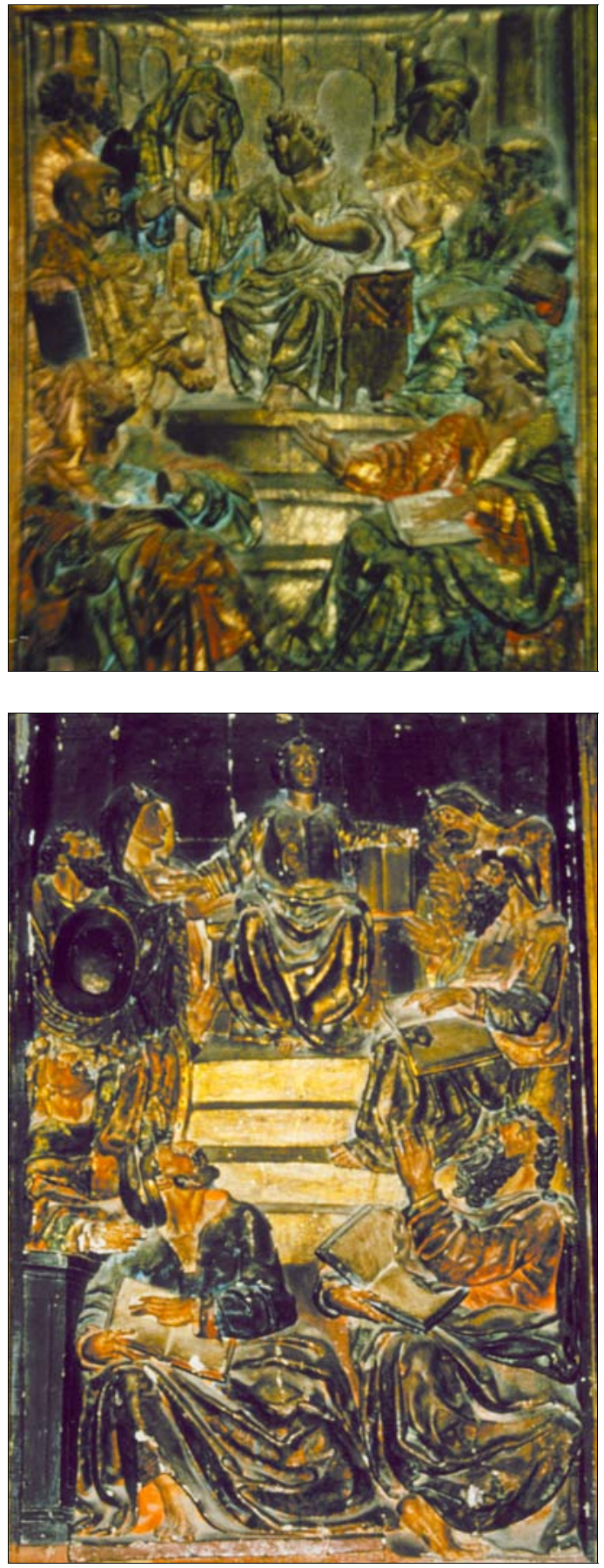

- Fig.23. Jesús entre los Doctores. Bartolomé Hernández. Retablo mayor de Bercianos de Vidriales. Tasado en 1591 (arriba dcha)

- Fig.24. Jesús entre los Doctores. Pedro de Villaba y Juan de Usinaga. Retablo Mayor de Huerga de Garab. C. 1600 (abajo izda)
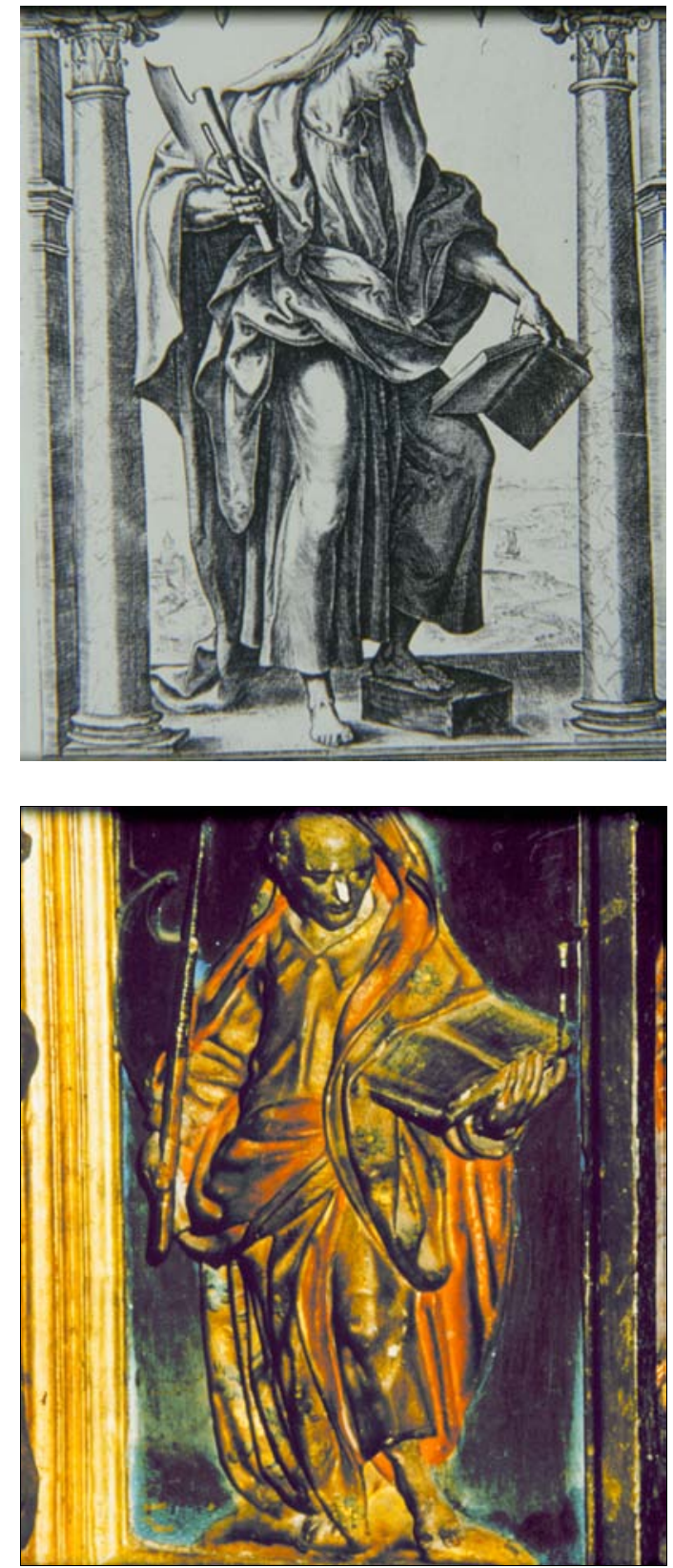

- Fig.25. San Matías Apóstol. Estampa de Hieronymus Wierix a partir de Maarten de Vos, formando parte de un Apostolado. 1578 (arriba dcha)

- Fig.26 San Matías Apóstol. Bartolomé Hernández. Retablo mayor de Bercianos de Vidriales. Tasado en 1591 (abajo dcha) 

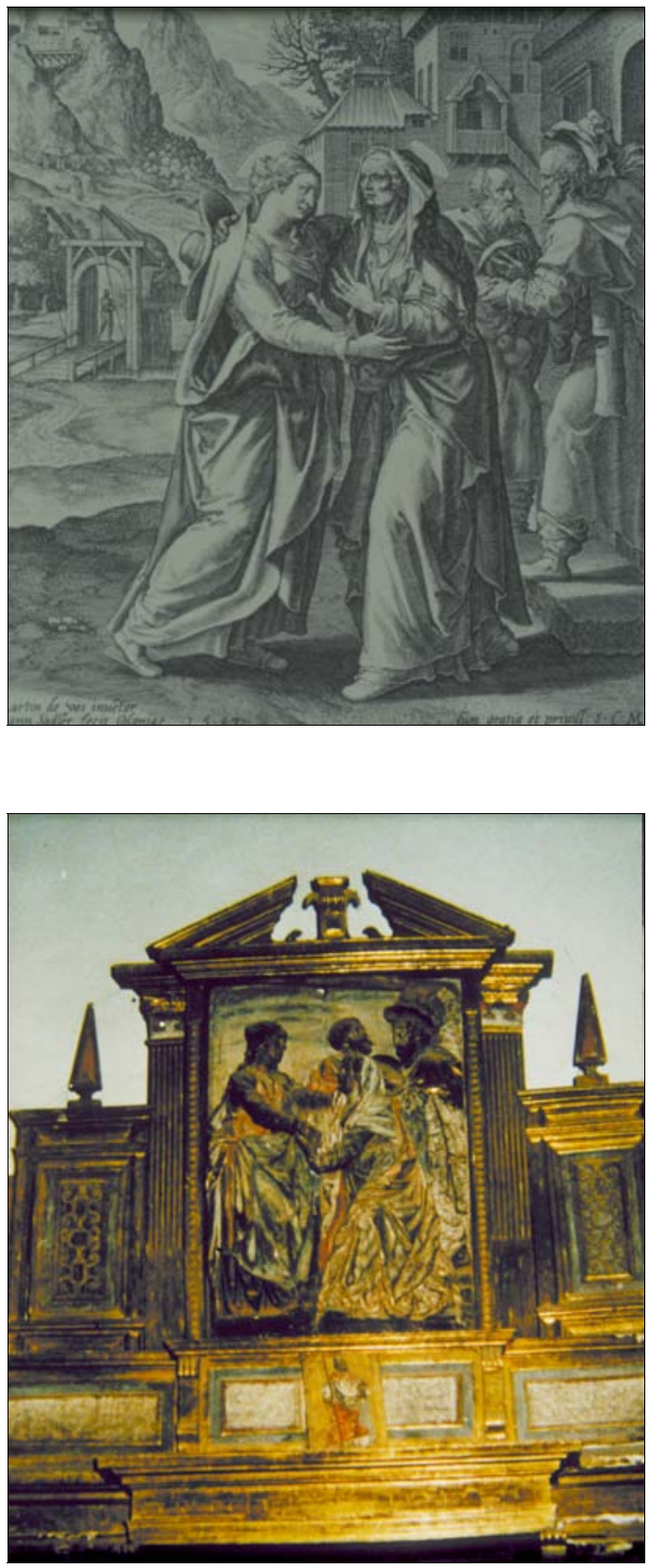

- Fig.27. Visitación. Estampa de Johan Sadeler a partir de Maarten de Vos. 1582 (arriba izda)

- Fig.28. Visitación. Bartolomé Hernández ?. Retablo de la Visitación de Granucillo de Vidriales. Primer cuarto del siglo XVII

(abajo izda)
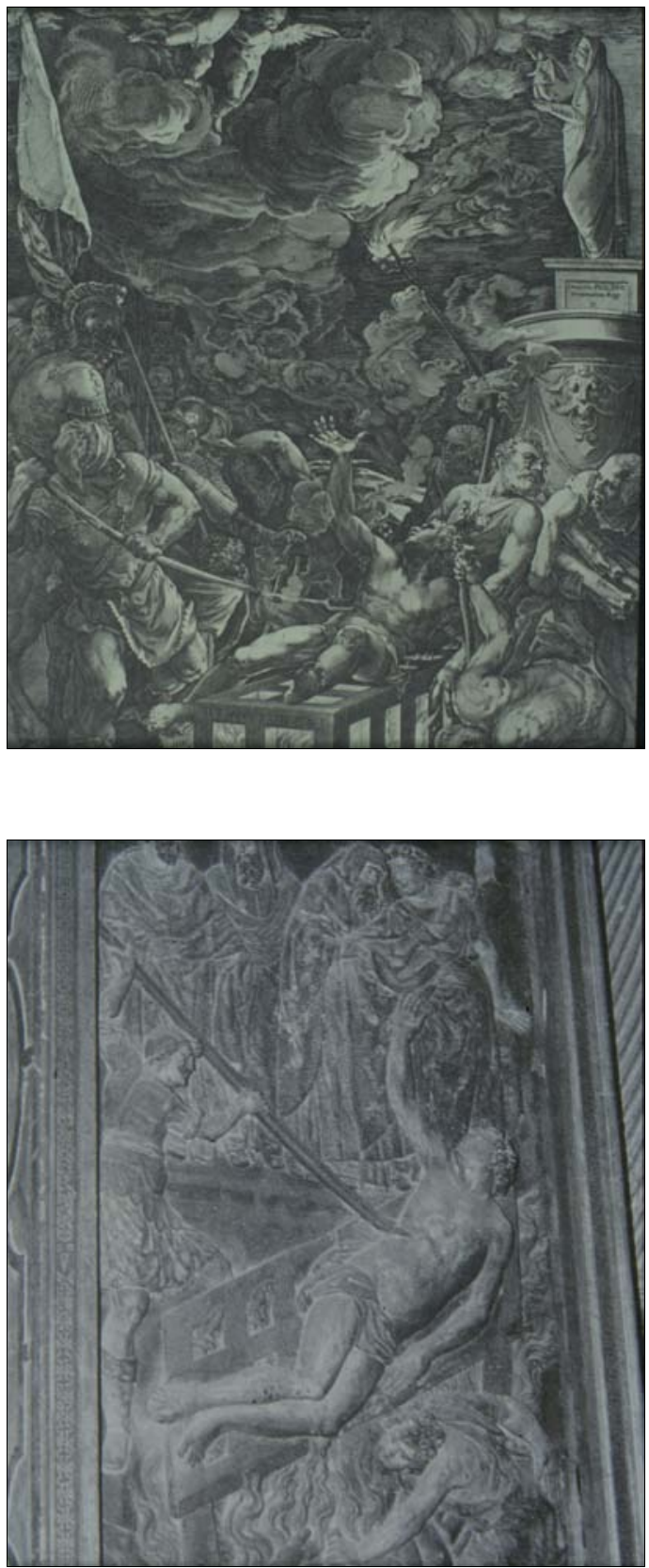

- Fig.29. Martirio de San Lorenzo. Estampa de Cornelis Cort a partir de Tiziano. Finales del siglo XVI

(arriba dcha)

- Fig.30. Martirio de San Lorenzo. Gregorio Español. Retablo mayor de Nogarejas. Tasado en 1610 (abajo dcha) 